\title{
REPERCUSIONES DE LA REVOLUCIÓN Y CÓMO CONTARLA EN EL ECO DE LOS PASOS: LA SECUENCIA INICIAL DE LA NOVELA DE JULIETA PINTO
}

\author{
Impact of the revolution and how to tell it in $\mathrm{El}$ eco de los pasos: \\ the opening sequence of Julieta Pinto's novel
}

\author{
Jorge Chen Sham*
}

\begin{abstract}
RESUMEN
La pregunta básica, que se plantea este trabajo sobre la novela El eco de los pasos (1979), de la novelista costarricense Julieta Pinto, reside en cuestionar la manera en la que la literatura aprehende y representa aquellos acontecimientos históricos catalogados de traumáticos para la memoria colectiva. Se trata de analizar la recuperación de hechos de una Historia no tan reciente y con una mirada distanciada, como la que brinda Julieta Pinto acerca de la Revolución del 48 y, para ello, se analiza el incipit enmarcado dentro de la secuencia inicial de la novela, en donde el motivo de la lluvia es el que desencadena la memoria y activa los recuerdos del personaje Ernesto.
\end{abstract}

Palabras clave: Revolución del 48, Julieta Pinto, El eco de los pasos, literatura costarricense, memoria histórica.

\begin{abstract}
This essay's main objective, which analyses the novel El eco de los pasos (1979) written by the Costa Rican novelist Julieta Pinto, is to question the method in which literature presents historic events labeled as traumatic in the collective memory. The objective is to analyze the recovery of the facts of such not a recent History seen from a distant gaze. This is what Julieta Pinto offers about the Revolution of 1948 and to that end, the incipit is analyzed and framed in the novel's initial sequence. It is in these initial words where the rain motif unchains the memory and it activates the remembrances of the character Ernesto. Key Words: Revolution of 1948, Julieta Pinto, El eco de los pasos, Costa Rican literatture, historic memory.
\end{abstract}

Universidad de Costa Rica, Profesor, Escuela de Filología, Lingüística y Literatura. Costa Rica Correo electrónico: jorgechsh@yahoo.com

Recepción: 14/3/16. Aceptación: 15/3/16. 
La memoria colectiva tiene modalidades para aprehender los acontecimientos que se viven como hitos y repercuten en los imaginarios colectivos. La pregunta básica sería cómo se abordan aquellos en la literatura, para que sea valorada, por ejemplo, tardíamente la Revolución del 48 parte de una narrativa que ofrece un punto de vista crítico y cuestionador de la Historia oficial. La línea de interpretación que esgrime Alexánder Sánchez es sumamente pertinente, al plantear dos maneras de ver esta "eclosión" de novelas a finales de los 70 del siglo pasado, cuando él habla de una "crisis de efectividad o de legitimidad" (Sánchez, 2011: 30) que intentan distanciarse de esa autoimagen nacional, la cual hace de la Revolución del 48 y la fundación de la Segunda República como "un acontecimiento indispensable para propiciar la modernización del país y la superación de los males crónicos como la corrupción, el nepotismo y el fraude" (2011: 25). De manera que, en un momento de crisis de ese modelo de Estado benefactor y de desarrollo social-demócrata que marcan las décadas entre los 50 y 70, las críticas que surgen propician, de rebote, que la literatura nacional aborde la distancia y contraste entre "los ideales patrióticos de justicia y reforma social que guiaron las luchas del 48 y el nuevo orden que se ha venido construyendo" (Quesada, 2000: 71).

\section{El eco de los pasos y el principio de la recapitulación autobiográfica}

Muy tardíamente en relación con la Revolución del 48, en efecto casi 30 años de su evento, Julieta Pinto publica El eco de los pasos (1979), y lo hace en plena efervescencia de la Revolución Sandinista y a partir del apresamiento en Costa Rica de Carlos Francisco Amador, uno de esos guerilleros baluartes de la insurrección y nos ofrece un balance a la distancia de los hechos del 48. En plena efervescencia de las guerras civiles centroamericanas y del triunfo de la Revolución sandinista, la narrativa costarricense $^{1}$ desarrolla un hito capital en la formación de la nacionalidad costarricense pero con un signo de negatividad y de fracaso de una revolución. En parangón, en la narrativa regional abundan los ejemplos de crítica a los regímenes de turno, en un momento de esperanza y fe en los proyectos utópicos y revolucionarios en toda Centroamérica (Cortez, 2009: 25); surgen una literatura testimonial por un lado, y por otro, una literatura de las izquierdas que propugnaba no sólo el derrumbamiento de los viejos órdenes, sino el advenimiento de uno nuevo bajo el espíritu de la solidaridad, de la lucha armada y de justicia socialistas.

Por lo tanto, el acercamiento que se impone, por supuesto, no es el político, sino se trata de tomar en cuenta la especificidad estética de la literatura y su propuesta de cómo aprehender "le domaine de l'appropiation du passé" (Robin, 1989: 47). Un pasado, en este caso, para el que se ha producido una distancia temporal (del 48 al 79 han pasado treinta años), lo cual permite plantear dos cosas: a) si ese desfase entre los acontecimientos y lo vivido ha necesitado tanto tiempo para ser digerido y asumido, por lo que se hablaría de un trauma, o b) el olvido y la emergencia de lo que se ha reprimido en tanto proceso tardío pero irreversible, qué determinaciones textuales e ideológicas provoca. En los dos casos, se trata de un aspecto disfórico que tiene mucho que decir en momentos de desintegración y de cuestionamiento, porque si una visión de mundo se tambalea y provoca el hastío o el desencanto, lo realiza en la medida en que la tragedia del duelo conlleva "la irremediable decrepitud de un mundo político que no puede ser otra cosa que historia de sufrimiento" (Leopold, 2010: 14). La decepción ante el presente, el futuro incierto que no se avizora, la frustración frente a un pasado de frustraciones y desaciertos, pueden conducir a una "reconstrucción paranoica de la realidad", indica Leopold, 2010: 14), este sería el ejemplo de Cachaza.

Pero, si el caso de la novela El eco de los pasos es diferente, porque Julieta Pinto asume la forma de una recapitulación autobiográfica, la cual corresponde a esa preocupación de índole cognoscitivo que problematiza la distancia entre el yo actual y lo vivido. El sujeto debe resolver 
esta distancia insalvable pues no puede contar "toda una vida" y debe discriminar, seleccionar:

\begin{abstract}
A decir verdad, sólo se puede evocar el pasado a partir del presente: la "verdad" de los días pasados existe sólo para la conciencia que, al recoger su imagen en la actualidad, no puede dejar de imponerle su forma y estilo: toda autobiografía aunque se ciña a pura narración, es una autointerpretación. (Starobinski, 1974: 67)
\end{abstract}

Toda interpretación de la vida o de los acontecimientos vividos es fidedigna y se articula sobre un proceso de memoria selectivo y de pertinencia interpretativa para dar entendimiento (claridad) a lo vivido. Sobre ello funciona la memoria como ejercicio esclarecedor que va actuando sobre el discurso en la medida en que perfila la propia conciencia. Dice Jacques Le Goff al respecto: "La memoria, como capacidad de conservar determinadas informaciones, remite ante todo a un complejo de funciones psíquicas, con el auxilio de las cuales el hombre está en condiciones de actualizar impresiones o informaciones pasadas, que él se imagina como pasadas" (1991: 129). Entonces, un hecho del presente actúa como desencadenante de la memoria en El eco de los pasos, tal y como ocurre también en Final de calle, de Quince Duncan.

\section{El incipit y el motivo de la lluvia}

La recapitulación autobiográfica, porque nace de la manera en que se seleccionan y se interpretan los hechos, surge cuando en $E l$ eco de los pasos, el personaje de Ernesto se confronta con su pasado. Para ello, Julieta Pinto escoge una novela de estructura discontinua y fragmentaria, que cuenta en una doble referencia histórica y narrativa: el presente frente al pasado; pero ¿qué lo desencadena en la novela? La importancia de la memoria está asegurada por el motivo seleccionado por Pinto en el incipit de la novela. La imaginación material de las "aguas" la relaciona Gaston Bachelard con el dinamismo y el movimiento; razón por la cual la corriente de un río o las aguas fluyentes (es decir, en movimiento) conducen a una "profunda ensoñación" (Bachelard, 2003: 18). En Julieta Pinto, el incipit o comienzo de la novela, valora el motivo de la lluvia del invierno tropical; su sentido, del agua que cae, es propio para redinamizar la idea de continuidad/discontinuidad por un lado, y por otro, el dinamismo del agua en movimiento. Esta imagen material es el motor para que la memoria fluya y desencadene el proceso de rememoración en la novela. En efecto, la instancia narrativa asume la perspectiva del observador de la lluvia en el espacio citadino; esta corre por las calles, mientras la "neblina", sometida al ejercicio de un pasado que se borra, transparenta unas imágenes algo huidizas y no tan claras:

Llueve. La lluvia de setiembre lava las calles, entrapa los paraguas, se desploma por las canoas y se detiene en los caños desbordados. La neblina diluye las figuras fantasmales que se ocultan en los resquicios de las puertas y el vaho húmedo desborda la avalancha de recuerdos sumergidos en los años. El fuerte tableteo produce sonidos extraños: golpes de tambor, ruidos de armas, quejas de mujeres, llantos de niños y penetra en los sepulcros para despertar las voces silenciadas que cuentan una historia... La misma historia en el encuentro de dos tiempos... (Pinto, 1979: 13)

El acto de observar la lluvia que cae es el motivo desencadenante de la nostalgia afectiva; el agua corre y se asocia con el movimiento y la fluidez. Dice al respecto Bachelard: "El agua se transforma así, poco a poco, en una contemplación que se profundiza, en un elemento de la imaginación materializante" (2003: 23), para que por otro lado, se encuentre ese elemento climático, la "neblina", el cual le otorga un estatuto ensombrecedor y a la vez que le permite a la conciencia transportarse. $\mathrm{La}$ "neblina" en cuanto motivo asociado al aire, es aquí necesario para activar también la conciencia y la memoria, porque "la avalancha de recuerdos" afloran y se van sucediendo (como el agua que corre por "canoas" y "caños", sin que tengan claridad ni lógica. Ellos irrumpen y, por eso se relacionan con la "neblina", es decir, algo que no está del todo esclarecido y que deberá, más bien, someterse al escrutinio de la memoria. 
Pero también, la asociación de imágenes auditivas activa la memoria, el "tableteo" del agua entra en una cadena metonímica con "golpes de tambor, ruidos de armas, quejas de mujeres, llantos de niños"; se trata de toda una enumeración que pondera el escenario de contienda bélica pasada, mientras que la otra imagen nos transporta a los cementerios en donde "penetra en los sepulcros para despertar las voces silenciadas que cuentan una historia".

El recuerdo inconexo del pasado, porque no hay una interpretación coherente inicial, es fragmentario y, por lo tanto, incoherente, pues no se le puede otorgar un sentido integral a esos hechos que afloran a la memoria, y eso a pesar de que se diga que es "la misma historia". Su estatuto y función son una empresa hermenéutica que se establecerá como deber de la historia o de la memoria en El eco de los pasos. Y lo es a causa de la relación causa/ consecuencia por dilucidar en la contigüidad, en donde el agua de la lluvia desencadena imágenes de dolor y de sufrimiento que vienen en forma fragmentaria: a) sonidos que no se pueden identificar o reconocer: "El fuerte tableteo produce sonidos extraños", y b) voces que, surgidas en los cementerios, claman por contar algo: "penetra en los sepulcros para despertar las voces silenciadas que cuentan una historia". Las "voces silenciadas" que, como esos fantasmas, se incrustan y se fijan en la escritura obliga a esa restitución que, en tanto ética y política, acomete la novela bajo el motivo de la lluvia.

Así se explicaría las razones por las cuales contar el pasado está en relación con lo que, en francés, se denomina como "la durée", la percepción del tiempo vivido, pues contar tiene siempre un valor eminentemente temporal y, en este caso, se narran/se actualizan acontecimientos ubicados en un pasado ya lejano (Chen Sham 2012: 121), pero que se intersectan con el presente, cuando se asegura en forma insospechada que "La misma historia en el encuentro de dos tiempos...", pues se trata aquí de una frase valorativa que subraya la circularidad del tiempo en su repetición absurda o trágica. Subyace aquí la noción del "eterno retorno", para evidenciar lo absurdo de un mundo que no puede renovarse eternamente; así se enfatiza el fracaso del progreso y que no corre hacia delante para renovar la Historia, por cuanto "[éste sería] el reconocimiento de que se han despilfarrado las fuerzas, la incertidumbre, la falta de ocasión de rehacerse de algún modo" (Muñoz, 1995: 32).

\section{La secuencia inicial de la novela y los sueños frustrados}

Para poner en balance tal sentido negativo de la Historia, debemos desbordar el incipit y plantear todo un análisis de la secuencia inicial de la novela. Su arquitectura fragmentaria obliga, en la contigüidad, a buscar qué elemento diegético es el que lo ha conducido: Ernesto se guarece de la lluvia que lo ha sorprendido caminando por las calles de la ciudad, entra en un café y lo abordan dos jóvenes que vienen de parte del guerrillero nicaragüense Carlos para pedirle su intervención ante las autoridades del país; lo increpan de la siguiente manera:

-Usted tiene amigos influyentes que pueden
ayudarlo a salir de la cárcel.

—_Amigos? Hace años no los trato.

- Fueron sus compañeros de lucha y oirán su petición.

—No hay duda de que la juventud los hace ser optimistas.

-Más bien los ideales. Creemos en la lucha de Carlos y haremos todo lo posible por ayudarlo.

Los miro con simpatía, casi con compasión. No puedo decirles que el tiempo vivido me ha demostrado que el ideal es un simple sueño [...]. Pero ese tiempo vivido, veinticinco años atrás, es un depósito aparentemente olvidado porque el más insignificante estímulo resucita imágenes sepultadas hace mucho tiempo y las superpone a la nitidez de las fotografías recién tomadas. (Pinto, 1979: $14-15)^{2}$

Más allá del referente histórico que sirve para desarrollar la trama de la historia en 
relación con el guerrillero Amador Fonseca, observemos que los jóvenes, con las inquietudes de los ideales políticos intactos, se enfrentan a la posición desengañada del excombatiente maduro, ya alejado de la política y de los círculos del poder. Su participación se describe en "Fueron sus compañeros de lucha", como esa insurrección en la que se levantaron en armas en contra de una causa justa. Pero las palabras de Ernesto son elocuentes, cuando contrasta los ideales de la juventud y su optimismo dinamizador con la categórica certeza del presente: "el ideal es un simple sueño". Pone en juego las ilusiones perdidas en tanto categoría negativa, falsa y engañosa y contrapuesta a la realidad presente (Marías 1990: 33), porque su valoración se establece frente a la capacidad de futuro y de expectativas por desarrollarse. Y el proceso de rememoración se desencadena aquí con ese referente temporal ("veinticinco años atrás") para que se revise, se analice, ahora lo que el texto llama "el tiempo vivido", el cual se denomina con pertinencia "depósito" en el que la memoria ahora va a indagar. El motivo de la lluvia persistente y que corre adquiere toda su fuerza en esta indagación. La memoria busca, entonces, en su intersección con el pasado, moldearse como inscripción y referencia que conlleva "la distinction entre l'avant et l'après" (Ricoeur 2000: 19). Se trata de acceder a un proceso de comprensión distanciado que conduzca a la puesta en marcha de mecanismos, cuya finalidad sea la responsabilidad de esclarecer y la verdad en el acto de rememoración. Aquí se exponen como si fueran "imágenes sepultadas hace mucho tiempo", es decir, enterradas pero que ahora se activan y surgen para ser recuperadas a partir de la mediación fotográfica. Así, se contrasta "la nitidez de las fotografías recién tomadas" con esos recuerdos que empiezan a emerger ahora con ebullición. El proceso de reflexión se asocia con la fotografía, porque el imperativo de recuperar/conservar se expresa para abordar "la destrucción del paso del tiempo, [frente a] los recuerdos" (Cuvardic García 2002: 64) que se disparan hacia el pasado. Su punto de referencia ya se anunció antes con la evocación de tiempo real transcurrido:
¡Veinticinco años atrás! La luna, una luna de marzo inmensamente grande, había subido al centro del firmamento y procuraba evadir las nubes oscuras que se arremolinaban, tratando de ocultarla.

En el portón de la finca esperabas la llegada de los compañeros. Habían quedado de reunirse esa misma noche para planear sus acciones en los próximos días. No podían continuar la vida cotidiana después de semejanza burla. El sufragio, sagrado en este país enclavado en el centro de las tiranías centroamericanas, había sido violado. [...] Y esta vez esa decisión de ustedes, ese grupo de muchachos de veinte a veinticinco años, que desde hacía mucho tiempo estudiaban los problemas del país para buscarles solución. Tenían en común el deseo de cambiar una estructura caduca que marginaba a las clases trabajadoras y era el primer intento serio, en muchos años, por enfrentarse a la realidad del país. [...]

Te temblaban las manos cuando las extendiste en señal de bienvenida y la palabra fraude quedó temblando en el viento del verano, que azotaba las ramas alunadas, en un marzo cargado de amenazas. (Pinto, 1979: 15).

El "portón de la finca" en el que Ernesto espera a los que se le unirán en la lucha adquiere toda su dimensión simbólica de umbral y de comienzo de unas aventuras colectivas. Los ideales juveniles se concretan en esa alusión a "ese grupo de muchachos de veinte a veinticinco años" que han tomado la decisión de rebelarse, mientras la insurrección se proyecta en contra del robo de las elecciones presidenciales y de un sistema que, se declara sin tapujos, no obedece a los intereses de las clases populares. Entonces, por relación de contigüidad, la novela programa aquí dos cosas:

1) Desde el punto de vista diegético, de dónde surgen las desilusiones actuales de Ernesto, cuando se ve confrontado por los muchachos que vienen a pedirle su mediación por Fonseca Amador y, entonces, recuerda su biografía personal aludiendo a sus ideales juveniles y a la vehemencia de sus palabras y gestos.

2) Desde el punto de vista histórico e ideológico, cuál es el referente político 
que motiva sus acciones pasadas y da sentido a su decisión de rebelarse, cuando alude a lo que Óscar Aguilar Bulgarelli ya narraba con prolijidad en su libro Costa Rica y sus hechos políticos de 1948, el estallido de la lucha armada y su frente sur con el levantamiento de Figueres Ferrer en su finca La Lucha (1969: 208-209).

Frente al "ideal" convertido en "simple sueño", las ilusiones de la juventud vienen a corroborar ese desfase que la Historia catapultará, por un lado y, por otro, el despertar a la realidad cruda de una revolución frustrada $\mathrm{y}$, tal vez, robada. Llama la atención cómo es la revolución que en los 70 se está llevando en Nicaragua la que desencadena el recuerdo y el deber de memoria. Por otra parte, en la medida en que la novela progrese, Ernesto se interesará más por el caso de Fonseca Amador, aprenderá a conocer y a ver en él el ejemplo de guerillero comprometido, lo cual le servirá para establecer un parangón consigo mismo.

Ahora bien, el proceso de rememoración por parte de Ernesto cubre los hechos del 48, él recuerda su participación y nos hace una revisión crítica a través de un distanciamiento/ desdoblamiento que la segunda persona del singular explicita en un juego de voces y de tratamiento pronominal: "En el portón de la finca esperabas la llegada de los compañeros", se indica en el inicio de esta escena de apertura para que la conciencia reavive el recuerdo vívido y ahora resplandeciente; mientras que en la escena de cierre se insiste en esa misma conciencia que le habla, su otro yo: "Te temblaban las manos cuando las extendiste en señal de bienvenida", con el fin de que los gestos y las acciones tengan esa actualidad. Se trata de un desdoblamiento de la conciencia, para que esos pedazos de un universo narrativo anterior interactúen con el presente. Pero la difracción de la conciencia en esta cita del comienzo del levantamiento armado y la insurrección tiene algo de problemático, cuando esa conciencia que le habla a Ernesto expresa tanto la cercanía que le ofrece el dirigirse a un vos ("En el portón de la finca esperabas la llegada de los compañeros"), como el distanciamiento o lejanía, cuando lo hace a un destinatario colectivo del que Ernesto formaba parte ("Y esta vez esa decisión de ustedes, ese grupo de muchachos de veinte a veinticinco años, que desde hacía mucho tiempo estudiaban los problemas del país para buscarles solución"). Aquí hay interacción entre dos pronombres, entre "vos" y "ustedes" y, en este sentido, tal "interacción no ofrece al observador un apoyo para la objetivación de todo el acontecimiento de acuerdo con el tipo monológico normal (argumental, lírica o cognitivamente) y hace participante, por lo tanto, también al observador" (Bajtín, 2005: 33-34). Esta interacción, entonces, problematiza los sucesos vividos y narrados, con ese acercamiento/ distanciamiento que conduce a un resultado de algo irresoluble.

Al utilizar el "vos" que, como alter ego le habla a la conciencia de Ernesto, Julieta Pinto le permite reconstruir sus ideales y su participación paso a paso desde que tomó la decisión de enrolarse en las filas de los sublevados. Su protagonismo asegura que él se presente como actor de la guerra y de una revolución en marcha desde estas primeras líneas del relato. Expresar este proceso se logra al alternar dos puntos de focalización narrativa, el externo (de más distancia con el personaje) en el que se narra algunos acontecimientos, se explica acciones y se resume el pensamiento político y social del personaje y de sus compañeros insurrectos, por ejemplo en: "Y esta vez esa decisión de ustedes, ese grupo de muchachos de veinte a veinticinco años, que desde hacía mucho tiempo estudiaban los problemas del país para buscarles solución". Aquí el punto de vista es el colectivo e incluye a Ernesto como a los otros en esa reunión entre el "vos" + ellos = "ustedes". Frente a esta focalización, se encuentra la interna (de más cercanía y proximidad), cuando se explican sensaciones y sentimientos a partir de los sentidos de Ernesto; el ejemplo magistral está al final de la secuencia analizada: "Te temblaban las manos cuando las extendiste en señal de bienvenida". Esta oscilación entre el punto de vista externo/interno le ofrece complejidad al 
movimiento de la conciencia, para que El eco de los pasos adquiera la forma de un relato en progresión y de alternancia, de indagación del pasado y reconstrucción de él.

\section{Balance de la secuencia inicial de El eco de los pasos}

Indica Julián Marías en relación con las ilusiones que estas obedecen a la prospección, a la posibilidad de cambio y de innovación que todo proyecto humano, sobre todo los juveniles, poseen. Eso es lo que desencadena el relato cuando el presente está marcado por el apresamiento de Carlos Fonseca Amador en Costa Rica, y Ernesto debe involucrarse en tanto profesor e intelectual universitario para lograr su libertad y reviva su propia experiencia personal y colectiva. Entonces, si sus ilusiones juveniles han tornado en lo contrario es porque esa interpretación del pasado no pasa la prueba del tiempo para que "[p]erderlas [sea] salir del error y alcanzar la verdad" (Marías 1990: 33).

Las preguntas se imponen: tenemos una estructura fragmentaria y discontinua que invita a tomar en cuenta, como indica el narrador: "La misma historia en el encuentro de dos tiempos" (Pinto, 1979: 13). Pero lo que provoca el proceso de memoria son sensaciones ligadas a la lluvia, la neblina, algo que despierta los fantasmas del pasado y que, en la novela, dibuja un malestar de sonidos y ruidos que rompen la caja de pandora de la conciencia. Se trata de un fuerte "golpeteo" incesante que no puede dejar incólume al narrador-protagonista; recordemos: "El fuerte tableteo produce sonidos extraños: golpes de tambor, ruidos de armas, quejas de mujeres, llantos de niños y penetra en los sepulcros para despertar las voces silenciadas que cuentan una historia..." (1979: 13). La negación y la neutralización del olvido se imponen aquí.

Entonces, los eventos históricos, que son comprendidos como traumáticos en la conciencia colectiva y en la historia nacional, repercuten en la literatura de una manera que debemos siempre estar atentos a analizar; entre estos destacan los conflictos bélicos y las revoluciones que de ellos se siguen. Para el caso de Costa Rica, habría que explicar las razones por las cuales lo que Alexánder Sánchez denominaba "narrativa del 48 " se hace esperar y no genera ni un balance ni una narrativa temprana de vencidos/vencedores. Efectivamente con Los vencidos, de Gerardo César Hurtado y Final de calle, de Quince Duncan, viene a completarse esta trilogía del 48 propiamente tematizada, con lo cual la Revolución del 48 también encuentra su lugar y su memoria. Habrá que esperar hasta lo que Beatriz Cortez denominó como "sensibilidad de posguerra", para que la producción estética costarricense "ya no expresase esperanza ni fe en los proyectos revolucionarios utópicos e idealistas que circularon en toda Centroamérica durante la mayor parte de la segunda mitad del siglo XX" (Cortez, 2009: 25). Se impone una crítica a estos proyectos utópicos y revolucionarios que, en la especificidad literaria, se materializan de una manera que debe tomar en cuenta lo estético, porque aquí hay una mirada reposada y distanciamiento temporal, y no se hace desde la cercanía histórica e ideológica, tal y como sucede con la novela de revolución mexicana ${ }^{3}$.

Desde Aristóteles la memoria se relaciona con el pasado y conlleva "la distinction entre l'avant et l'après" (Ricoeur, 2000: 19), así percibida por la conciencia humana y grabada sobre la memoria que la moldea en tanto inscripción y referencia. Tratándose de la acción de recordarse, Aristóteles distingue el simple recuerdo que se produce por una afección y la búsqueda activa del recuerdo; de esta manera, recordar el pasado plantea el problema de la distancia temporal y la problemática de la representación histórica de lo que sucedió. Así en esta novela de Julieta Pinto, entre los ideales juveniles de acción y de cambio del mundo y la situación actual de corrupción, de la pérdida de los valores y de los intríngulis del poder, El eco de los pasos planteará el desengaño. La novela hace de la revolución un evento fallido, planteando así la marcha del protagonista hacia la insurrección como algo que solamente está en el recuerdo más íntimo de las "ilusiones" de un sueño de juventud; de ahí la distancia de lo evocado, cuando el título aborda "los 
pasos". En tanto sinécdoque de la marcha y del levantamiento, esos "pasos" son solamente un "eco" ya, no una realidad perceptible y clara de un sonido nítido: apenas un "eco" a la luz de la distancia temporal, porque el olvido y la decepción se han impuesto. De esta manera, la reinserción de ese pasado es problemática en la medida en que el ideal revolucionario, su compromiso y sus luchas siguen situándose en la melancolía y dentro de esa tragedia del duelo ante el fracaso ${ }^{4}$ (Chiani, 2014: 420-421). Tal es la lectura de la secuencia inicial que deberá completarse cuando se aborde la totalidad de una novela rica en matices estilísticos y de un manejo pertinente de la crisis del personaje.

\section{Notas}

1. Ya sabemos que este ciclo de la Revolución lo empieza, Quince Duncan y Gerardo César Hurtado. Más recientemente Alexánder Sánchez Mora inserta a Cachaza de Virgilio Mora en este ciclo (Sánchez, 2011: 19-34).

2. Si no hay indicación alguna, las cursivas pertenecen al texto de Julieta Pinto.

3. Pensando en el caso de Los de abajo (1916), de Mariano Azuela.

4. Lo anterior implica que esta tragedia del duelo no necesariamente debe tener una narración caótica, pero sí debe ser fragmentaria y discontinua, como lo es en Julieta Pinto.

\section{Bibliografía}

Aguilar Bulgarelli, Óscar. 1969. Costa Rica y sus hechos politicos de 1948 (Problemática de una década). San José: Editorial Costa Rica.

Bachelard, Gaston. 2003. El agua y los sueños: Ensayo sobre la imaginación de la materia. México, D. F.: Fondo de Cultura Económica, $4^{\mathrm{a}}$. reimpresión.
Chen Sham, Jorge (Ed.). 2011. La narrativa de Virgilio Mora: Complejidad polifónica y dialogismo. Heredia: Editorial Fundación INTERARTES.

Chen Sham, Jorge. 2012. "Repercusiones de la Revolución Sandinista en la novela nicaragüense: Rosario Aguilar y Conny Palacios". En Études Romanes de Brno XXXIII (2): 121-132.

Chiani, Miriam. 2014. "Lecturas de la derrota y el fracaso en la producción narrativa y crítica de Marcelo Cohen". En Revista Iberoamericana LXXX (247): 399-432.

Cortez, Beatriz. 2009. Estética del cinismo: Pasión y desencanto en la literatura centroamericana de posguerra. Ciudad de Guatemala: F \& G Editores.

Cuvardic García, Dorde. 2012. "Punctum fotográfico y construcción de la memoria personal y colectiva en Escenas del cine mudo, de Julio Llamazares". En Études Romanes de Brno XXXIII (2): 59-71.

Folger, Robert y Stephan Leopold (Eds.). 2010. Escribiendo la Independencia: Perspectivas postcoloniales sobre la literatura hispanoamericana del siglo $X I X$. Madrid/ Frankfurt am Maim: Iberoamericana/ Vervuert.

Le Goff, Jacques. 1991. El orden de la memoria: el tiempo como imaginario. Barcelona: Editorial Paidós.

Leopold, Stephan. 2010. "Introducción: ¿y cómo se escribe la Independencia?". En Folger y Leopold (Eds.): 7-19.

Marías, Julián. 1990. Breve tratado de la ilusión. Madrid: Alianza Editorial. 2a . reimpresión. 
Muñoz Barquero, Elizabeth. 1995. "Eterno retorno e historia: El caso de Nietzche". En Revista de Filosofía de la Universidad de Costa Rica XXXII (80): 31-39.

Pinto, Julieta. 1979. El eco de los pasos. San José: Mésen Editores.

Quesada, Álvaro. 2000. Breve historia de la literatura costarricense. San José: Editorial Porvenir.
Ricoeur, Paul. 2000. La mémoire, l'histoire, l'oubli. París: Éditions du Seuil.

Robin, Régine. 1989. Le roman mémoriel. Longueil: Les Éditions du Préambule.

Sánchez Mora, Alexánder. 2011. "Cachaza va a la guerra: la locura y la pesadilla de la Guerra Civil de 1948". En Chen Sham (Ed.): 19-34.

Starobinski, Jean. 1974. La relación crítica (Psicoanálisis y Literatura). Madrid: Ediciones Taurus.

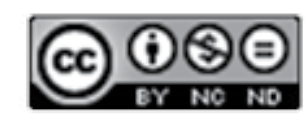

Este obra está bajo una licencia de Creative Commons

Reconocimiento-NoComercial-SinObraDerivada 4.0 Internacional. 
